\title{
Prevalence of menopausal symptoms and perceptions about menopause among postmenopausal women attending Gynaecology OPD at GMC Idukki, India
}

\author{
Leena A. Joseph ${ }^{1}$, Acka Priya Varghese ${ }^{2 *}$
}

\author{
${ }^{1}$ Department of Obstetrics and Gynaecology, Govt. Medical College, Idukki, Kerala, India \\ ${ }^{2}$ Department of Obstetrics and Gynaecology, Govt. Medical College, Kottayam, Kerala, India
}

Received: 06 January 2017

Accepted: 11 January 2017

\section{*Correspondence: \\ Dr. Acka Priya Varghese, \\ E-mail: davidsg123@yahoo.co.in}

Copyright: (c) the author(s), publisher and licensee Medip Academy. This is an open-access article distributed under the terms of the Creative Commons Attribution Non-Commercial License, which permits unrestricted non-commercial use, distribution, and reproduction in any medium, provided the original work is properly cited.

\begin{abstract}
Background: Idukki is a hilly tract area in the state of Kerala. No studies regarding menopause has been reported from Idukki. This study is done among postmenopausal women in an attempt to shed light on the prevalence of menopausal symptoms and perceptions of postmenopausal women in a panchayat in Idukki district which is typically a rural area. Primary objectives of the study were to find the prevalence of menopausal symptoms in post-menopausal women attending the outpatient department of Government Medical College, Idukki, India and to find the perceptions about menopause among these post-menopausal women. Secondary objectives were to find the mean age and pattern of attainment of menopause among postmenopausal women and to find the treatment seeking behavior of the postmenopausal women residing in this area.

Methods: A cross-sectional observational study is done among 100 postmenopausal women attending the outpatient department of Obstetrics and Gynaecology. Questions are asked based on interview schedule. The results are then analyzed.

Results: The mean age of menopause was $45.69 \pm 4.35 .78 \%$ of population had one or more symptoms in the menopausal period. Only $19.5 \%$ of the symptomatic women took treatment. $77 \%$ had positive perceptions.

Conclusions: The awareness of these women in this area is poor thus limiting the treatment seeking behavior. Improvement of awareness is a must to improve the quality of life of post-menopausal women.
\end{abstract}

Keywords: Mean age of menopause, Prevalence of menopausal symptoms, Perceptions

\section{INTRODUCTION}

Menopause is an accepted, universal phenomenon that occurs in a woman's life. World Health Organization has defined a post-menopausal lady as a woman who have stopped having menstrual bleeding one year ago or stopped having periods as a result of medical or surgical intervention. Natural Menopause usually occurs in the midlife stage. Symptoms of menopause may be overcome easily or can make a woman's life miserable. As a woman spends one third of her life in this phase, severe menopausal symptoms reduce the quality of life of a woman. ${ }^{1}$ Early recognition of symptoms and its treatment can alleviate this distressing condition of many a woman. Hence menopausal health demands high priority in India. Majority of the Indian population reside in rural areas where the health care system is less available and menopausal complaints are likely to be ignored. The state of Kerala has high literacy rate and good health care system. But Idukki is one of the hilly tract areas and medical care system is not easily available as rest of the State. Research study on post-menopausal women from this area has not been reported. This study is therefore expected to bring out the magnitude of suffering due to health issues among post-menopausal women in a panchayat of Idukki. 


\section{METHODS}

The study was done as a cross sectional observational study. This study was conducted among 100 postmenopausal women who attended the Department of Obstetrics and Gynaecology, Government Medical College Idukki. Convenient sampling was followed. The sample size was calculated taking a prevalence of $80.5 \%$ as per the previous study. ${ }^{2}$ An error of $8 \%$ was taken and the sample size came as almost 100 . Hence in this study 100 post- menopausal women were taken for study.

\section{Inclusion criteria}

All post-menopausal ladies who attained menopause more than one year willing to take part in the study were included.

\section{Exclusion criteria}

1. Ladies having serious disease or mental retardation.

2. Ladies with unnatural menopause.

3. Ladies on anti-depressant therapy or those with any recent mishap or trauma in her life.

Prior permission was obtained from the ethical committee of Government Medical College Idukki. The ladies who satisfied the inclusion criteria were asked questions based on an interview schedule. Informed consent was obtained. The demographic factors studied were age, religion, education and occupation. Questions were asked to find out the pattern of cessation of menstruation, the age at which they attained menopause, their menopausal symptoms like excessive sweating, hot flushes, irritability, depression, vaginal irritation, decreased libido, lethargy, forgetfulness, and head-ache. There were questions to find out any abnormal uterine bleeding. Questions were also asked to know whether they felt the need to visit the doctor for these symptoms so as to know the treatment seeking behaviour. Their awareness regarding the availability of treatment was asked. We also asked questions to know how these women perceived their menopause. The answers were scored and the perceptions were considered as positive or negative depending on scores.

These postmenopausal ladies were given treatment for their symptoms. Those with negative perceptions were counselled and these ladies were given information regarding menopause and when to seek treatment.

\section{Statistical analysis}

Data was coded, entered and analyzed using Microsoft Excel.

\section{RESULTS}

This study was done in 100 postmenopausal women. The mean age of the study population was 60.86 years with a standard deviation of 8.50 . The highest age was 85 and the lowest age was 48 years.

Christians formed majority of the study population. 71 of them were Christians; while 26 of them were Hindus and only 3 of them (3\%) were Muslims.

20 people had passed their class X. 39 people had secondary education, 34 had primary education and 7 were illiterate. None had college education.

Among these 100 women only 3 were employed (3\%). $69 \%$ of women in the present study were married, while $31 \%$ were divorced, single or widowed.

Distribution of women based on socio-demographic variables is shown in Table 1.

Table 1: Distribution of women based on sociodemographic variables.

\begin{tabular}{|lll|}
\hline Variables & & Percentage \\
\hline Mean Age & & $60.86 \pm 8.50$ \\
\hline Religion & Christian & 71 \\
\hline & Hindu & 26 \\
\hline & Muslim & 3 \\
\hline Education & Literate & 93 \\
\hline & Illiterate & 7 \\
\hline Occupation & Employed & 3 \\
\hline & Unemployed & 97 \\
\hline Marital Status & Married & 69 \\
\hline & Single/Divorced/ & 31 \\
\hline $\begin{array}{l}\text { Prevalence of } \\
\text { symptoms }\end{array}$ & Present & 78 \\
\hline & Absent & 22 \\
\hline
\end{tabular}

While analyzing the pattern of cessation of menstruation at menopause, $44 \%$ had gradual cessation of menstruation, $40 \%$ had irregular cycles followed by cessation, while the rest $16 \%$ had sudden cessation of menstruation.

The mean age of menopause was 45.69 with a standard deviation of 4.30 .

It was found that 78 women among these 100 women (78\%) had one or more of post-menopausal symptom, while $22(22 \%)$ of them were asymptomatic. Hot-flush was the commonest complaint with $58 \%$ of them suffering from it. 50\% had vaginal dryness and irritation, $42 \%$ had excessive sweating, $17 \%$ had irritability, and $10 \%$ had lethargy. Another 8 suffered from depression, $6 \%$ of them suffered from decreased libido, another $6 \%$ had forgetfulness and 2\% women had head-ache. Many women had more than one symptom. 14 of them had more than four symptoms. 
$71 \%$ of the population was not aware of any reason for menopause. $29 \%$ thought that the menopause was age related.

Though 78 women suffered from post-menopausal symptoms, only 15 women (19.23\%) who were symptomatic had gone to a doctor for treatment of postmenopausal symptoms. Among the symptomatic ladies, $55(70.51 \%)$ thought that these symptoms were part of menopause and cannot be treated, while 8 women $(10.26 \%)$ suffered in silence because they were ashamed to go to a doctor with their symptoms. $91 \%$ had symptoms in the first 5 years of post-menopausal life, while only $9 \%$ had it after 5 years of menopause. Treatment seeking behaviour is shown in Figure 1.

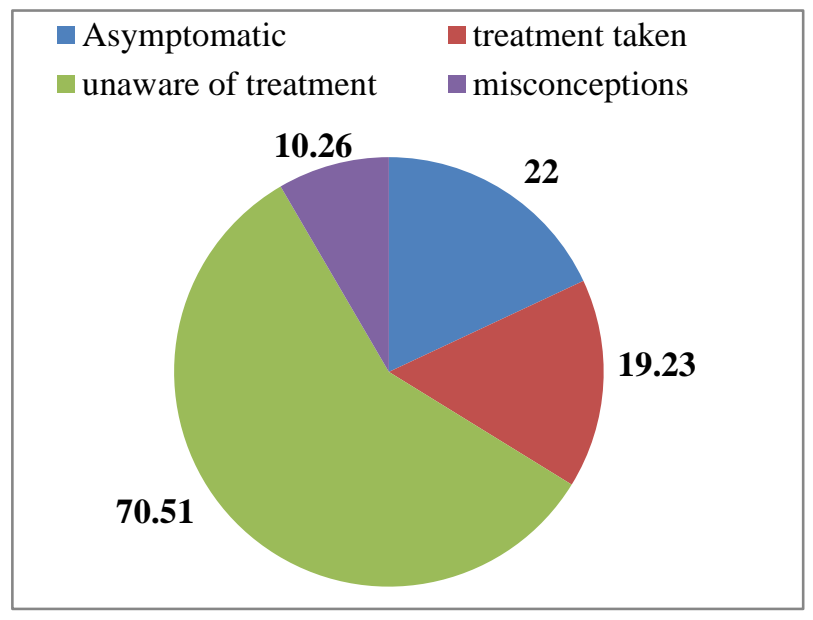

Figure 1: Treatment seeking behaviour.

$87 \%$ of ladies did not take any medication for these symptoms. Only $13 \%$ of these ladies took any medication. 2 people used modern medicine, 5 people used Ayurvedic preparation, and 6 used homeopathic preparation. All these ladies had seen a doctor before taking the medication.

36 of these women (36\%) knew that bleeding per vaginum, discharge per vaginum, post coital bleeding in the post-menopausal period were abnormal. While the rest $64(64 \%)$ were not sure whether it was normal or abnormal.

$47 \%$ percent accepted their menopause without any regrets as a normal process of ageing. A $38 \%$ of these women perceived that menopause liberated them from worries of menstruation and pregnancy. $13 \%$ had the perception that they became old after menopause. $10 \%$ of women thought that they lost their womanhood with menopause. $6 \%$ perceived that they regretted losing their youth, while another $4 \%$ had regrets in losing their fertility. It was seen upon scoring the responses regarding perceptions, that $77 \%$ of these women had positive perceptions while $23 \%$ of them had negative perceptions.

\section{DISCUSSION}

Mean age of the study population was $60.86 \pm 8.5$. In the study by Borkar et al, the mean age of the study population was 56.7. ${ }^{3}$ It was noted that among the 100 women, $93 \%$ were educated. At Kannur which is another state of Kerala, $96.3 \%$ were educated. ${ }^{3}$ Kerala is the state with highest literacy rate in India. In the study by Alakananda et al, $26 \%$ of the population at Guwahati was uneducated. $^{2}$ Christians form the majority in this study. This may be peculiar to this area of Idukki.

The pattern of cessation of menstruation at menopause is similar to the study by Alakananda et al, as shown in Table 2. ${ }^{2}$

Table 2: Comparison of pattern of cessation.

\begin{tabular}{|lll|}
\hline $\begin{array}{l}\text { Pattern of } \\
\text { cessation }\end{array}$ & Present study & Alakananda et al \\
\hline Gradual & 44 & 45 \\
\hline Irregular & 40 & 38.5 \\
\hline Sudden & 16 & 16.5 \\
\hline
\end{tabular}

Age of menopause for the present study was 45.91 \pm 3.9 . The mean age of menopause is similar to the other studies in different part of India as shown in Table 3.

Table 3: Comparison of mean age of menopause.

\begin{tabular}{|llll|}
\hline $\begin{array}{l}\text { Sl. } \\
\text { No. }\end{array}$ & Studies & Place & $\begin{array}{l}\text { Age at } \\
\text { menopause }\end{array}$ \\
\hline 1 & Present study & Idukki, Kerala & $45.91 \pm 3.9$ \\
\hline 2 & Alakananda et al $^{3}$ & Guwahaty & $46.35 \pm 4.07$ \\
\hline 3 & ${\text { Akansha et } \mathrm{al}^{4}}^{\text {Nkarinder }}$ & Delhi & $46.24 \pm 3.38$ \\
\hline 4 & $\begin{array}{l}\text { Narimachal } \\
\text { Mahajan et al }\end{array}$ & $\begin{array}{l}\text { Himadesh } \\
\text { Prad }\end{array}$ & 44.54 \\
\hline 5 & Borkar $^{2}$ & Kannur & 48.26 \\
\hline
\end{tabular}

In the present study, $78 \%$ of study population had at least one or more post-menopausal symptom. In the study by Akansha et al, it was $89.3 \%$ and that by Alakananda et al, it was $80.5 \%$ which is almost similar to the present study. ${ }^{2,4}$

Hot flushes were the most common symptoms with $58 \%$ suffering from it while $42 \%$ had excessive sweating. In the study by Alakananda et al, it was $52.5 \%$ and $48.5 \%$ respectively which is comparable with this study. ${ }^{2} 50 \%$ suffered from vaginal dryness and irritation. This is comparable to the study by Borkar et al, in which it was $55.3 \%{ }^{3}$

$71 \%$ of them did not know the reason why menopause occurs. Among the 78 symptomatic women, only $19.5 \%$ went to a doctor for treatment. $70.5 \%$ of them were not aware of any treatment available for their menopausal symptoms and therefore they suffered silently. $10 \%$ were ashamed to go to a doctor. This is almost similar to a 
study by Alakananda et al, where $69.5 \%$ did not seek treatment. ${ }^{2}$ Another point of concern is that only $36 \%$ of women were aware that symptoms like discharge per vaginum, bleeding per vaginum in the postmenopausal period were abnormal and needs evaluation and treatment. Inspite of the high literacy rate, the awareness among these women regarding menopause was low in this Panchayat in Idukki. It is seen that ignorance is altering the treatment seeking behaviour. Thus from this study it is emphasized that steps should be taken to increase the awareness among these postmenopausal women. This can better be done involving the primary health centres. This is likely to improve the treatment seeking behaviour of the patients.

It is indeed a good thing that $100 \%$ of women who took treatment had seen a doctor. This is strikingly different from Alakananda et al, study where majority of people took medication without consulting a doctor. ${ }^{2}$ Thus these women are willing to see a doctor if their awareness is improved. This again points to the fact that improving the awareness among the women in this area will alter the treatment seeking behaviour of the people.

Majority of the symptomatic women said that their symptoms were more in the first five years of postmenopausal life and that it decreased later. Similar results were seen in the study at Guwahati and Iran. ${ }^{2,6}$

Majority of the study population were having positive perceptions. Perceptions of these women were scored and it was found that $77 \%$ of women had positive perceptions. In the study by Wong et al, $70.76 \%$ had positive perceptions. ${ }^{7}$ It is important to correct the negative perceptions of women. This can be achieved by proper counselling and increasing the awareness among women.

\section{CONCLUSION}

The study is attempted to find out the prevalence of menopausal symptoms and perceptions regarding menopause in a Panchayat in Idukki, Kerala, where the health care system is limited when compared with rest of the State. Though majority of the study population suffered from menopausal symptoms only a few took treatment. Lack of awareness and misconceptions led others to suffer in silence. By initiating positive steps for increasing awareness among women in this area can improve the quality of life of middle aged and elderly women.

Funding: No funding sources

Conflict of interest: None declared

Ethical approval: The study was approved by the Institutional Ethics Committee

\section{REFERENCES}

1. Vaze N, Joshi S. Yoga and menopausal transition. J Midlife Health. 2010;1:56-8.

2. Alakananda, Das N, Das BP. Age of Menopause and Menopausal Symptoms among women attending Gauhati Medical College and Hospital, Guwahati, Assam: A cross-sectional study. Scholars Journal of Applied Medical Sciences (SJAMS). 2015;3(7C):2621-9.

3. Borker SA, Venugopalan PP, Bhat SN. Study of menopausal symptoms, and perceptions about menopause among women at a rural community in Kerala. J Midlife Health. 2013;4(3):182-7.

4. Singh A, Pradhan SK. Menopausal symptoms of postmenopausal women in a rural community of Delhi, India: A cross-sectional study. J Midlife Health. 2014;5(2);62-7.

5. Mahajan N, Aggarwal M, Bagga A. Health issues of menopausal women inNorth India. Journal of Midlife Health. 2012;3(2):84-7.

6. Abedzadeh-Kalahroudi M, Taebi M, Sadat Z, Saberi F, Karimian Z. Prevalence and Severity of Menopausal Symptoms and Related Factors among Women 40- 60 Years in Kashan, Iran. Nursing and Midwifery Studies. 2012;1(2):88-93.

7. Wong LP, Nur Liyana AH. A survey of knowledge and perceptions of menopause among young to middle-aged women in federal territory, Kualalumpur, Malaysia. JUMMEC. 2007;10(2):2230 .

Cite this article as: Leena AJ, Varghese AP. Prevalence of menopausal symptoms and perceptions about menopause among postmenopausal women attending Gynaecology OPD at GMC Idukki, India. Int J Reprod Contracept Obstet Gynecol 2017;6:413-6. 